Canadian Journal of Fisheries and Aquatic Sciences

Canadian

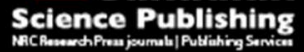

Journal canadien des sciences halieutiques et aquatiques

Food availability in spring affects smolting in brown trout (Salmo trutta).

\begin{tabular}{|r|l|}
\hline Journal: & Canadian Journal of Fisheries and Aquatic Sciences \\
\hline Manuscript ID: & cjfas-2015-0106.R2 \\
\hline Manuscript Type: & Article \\
\hline Date Submitted by the Author: & 06-Jul-2015 \\
\hline Complete List of Authors: & $\begin{array}{l}\text { Jones, Douglas; University of Otago, Department of Zoology } \\
\text { Bergman, Eva; Karlstad University, Biology } \\
\text { Greenberg, Larry; University of Karlstad, Biology }\end{array}$ \\
\hline Keyword: & $\begin{array}{l}\text { FRESHWATER < Environment/Habitat, STREAMS < Environment/Habitat, } \\
\text { FRESHWATER ENVIRONMENT < General, MIGRATION < General }\end{array}$ \\
\hline \multicolumn{2}{|c}{} \\
\hline
\end{tabular}

SCHOLARONE"

Manuscripts 


\section{Food availability in spring affects smolting in brown trout (Salmo trutta).}

Douglas A. Jones ${ }^{1,2}$, Eva Bergman ${ }^{1}$ and Larry Greenberg ${ }^{1}$

${ }^{1}$ Department of Biology, Karlstad University, 651 88, Karlstad, Sweden

${ }^{2}$ Department of Zoology, Otago University, P.O. Box 56, Dunedin 9054, New Zealand

Corresponding author: Douglas Jones (e-mail: jondo802@student.otago.ac.nz) 


\section{Abstract}

2 Prior to out-migration, salmonid fish typically undergo physiological and morphological

3 changes - a process known as smolting. This study indicates that smolting in brown trout

4 (Salmo trutta) is affected by feeding conditions in spring immediately prior to out-migration.

5 This conclusion was reached after experimentally testing the effect of seasonal variation in

6 food availability on smolt status in the spring. A migratory strain of trout was administered

7 either high $(\mathrm{H})$ or low $(\mathrm{L})$ food rations in the autumn, winter or spring prior to release in the

8 spring. Whilst fish growth or condition could be affected in any season, it was spring

9 rationing that reduced growth and growth-related variables and which caused increased

10 smolting. Our result supports the idea that smoltification and the decision to migrate is

11 affected by spring food availability regardless of conditions in the previous autumn or winter.

14 Key words: food rationing, smolt, migration, growth 


\section{Introduction}

Salmonid migrations are some of the best described and understood in the animal kingdom. An initial out-migration from where an individual is spawned is accompanied by a return migration to the place of origin for subsequent spawning. From an evolutionary perspective, migration in salmonids occurs when the cost is less than the benefit of migrating (Gross et al. 1988, Bohlin et al. 2001). The cost is related to energy expenditure and mortality, and the benefit is measured in reproductive fitness and growth (Jonsson and Jonsson 1993). A "conditional strategy" has been proposed to operate in salmonid migratory decision making (Metcalfe et al. 1988, Wysujack et al. 2009, Morita et al. 2014). According to the conditional strategy, the threshold switch-point or liability for migration is related to growth or some variable correlated with growth. Another way to view migration is to describe it as a probabilistic reaction norm (Heino et al. 2002, Kuparinen et al. 2008).

Other indices of fish state related to growth and implicated in migratory decision making are size, metabolic rate, condition factor, lipid content and energetic state of the fish (Jonsson and Jonsson 1993, Forseth et al. 1999, Morgan et al. 2002, Boel et al. 2014). These traits are influenced by biotic (i.e. food) and abiotic (temperature) environmental factors (Elliott 1994, Railsback and Rose 1999), which determine if migration will be undertaken. A compelling biotic environmental factor linked to migratory decision making in salmonids is food availability, where the number of migrants can be increased by reducing the amount of food fish receive (Keeley 2001, Wysujack et al. 2009, Vainikka et al. 2012).

Many studies exploring the link between food and migration in salmonids have used brown trout (Salmo trutta), which is plastic in its life history tactics, exhibiting the full range of migratory behaviours described for salmonids (Klemetsen et al. 2003). Moreover, the decision to migrate in brown trout has been shown to be influenced by environmental conditions (Olsson et al. 2006). In studies using brown trout, reducing the amount of food has 
49 been shown to increase the number of migratory fish (Wysujack et al. 2009, Bergman et al.

50 2013). Most studies have only examined the effect of constant starvation or satiation on

51 migration (see for example Wilzbach 1985, Keeley 2001, Imre et al. 2004, Wysujack et al.

52 2009) over a fixed period of time. An exception to this is the study of Pirhonen and Forsman

53 (1998) in which fish were given different food rations from May - November and then full

54 rations until spring when smolting behaviour was assessed. Studies involving starvation

55 usually show that starvation affects migration, but cannot identify if starvation has different

56 effects on the fish's migratory response, dependent on when and how long the starvation

57 occurs. The closely related Atlantic salmon (Salmo salar) migrate in spring, based on their

58 state $\sim 9$ months before the migratory event (Metcalfe et al. 1986, 1988). If a predetermined

59 "threshold" state is reached soon after midsummer, then salmon migrate the following spring.

60 If not, they delay migratory decision making for another year. More recently, Vainikka et al.

61 (2012) have presented other results, showing that winter and spring rationing prior to

62 outmigration can increase smoltification and migration tendency in Atlantic salmon. It is

63 unclear when brown trout decide whether or not to migrate.

65 In this study we investigate how food rationing during autumn, winter or spring affects brown

66 trout's state (size, condition, lipid content) and migratory readiness (indicated by smolting).

67 Our hypothesis was that a greater proportion of starved fish would smolt than fish fed full

68 rations. More specifically, the number of fish smolting should increase in spring when food

69 was restricted as compared to fish fed full rations - regardless of previous food availability in

70 autumn or winter. This should also be reflected by differences in fish state, with spring-

71 starved fish displaying lower growth, condition and lipid reserves than fish fed to satiation. 


\section{Methods}

\section{Ethical statement}

75 The protocol was approved by the Gothenburg Animal Review Board (Permit number 249-

76 2010). The study was conducted in strict accordance with the ethical guidelines stated in the

77 permit. The fish used in the study were hatched and reared at the Gammelkroppa fish

78 hatchery, north of Filipstad, Sweden. Fish were anaesthetized with tricaine mesylate prior to

79 measuring, and animals sacrificed for fat content analysis were euthanised using a high dose

80 of tricaine mesylate.

\section{Study area}

82 The experiment took place from 29 September 2010 - 18 May 2011 at Brattfors fish farm,

83 mid-western Sweden (N 59 $67^{\prime}$; E $\left.14^{\circ} 02^{\prime}\right)$, using hatchery brown trout raised by

84 Gammelkroppa fish farm. Prior to the experiment, fish were reared at high densities in

85 circular tanks outdoors (50 m squared; water depth $120 \mathrm{~cm}$ ). Water flow was continuous and

86 supplied by a nearby lake (Yngen). Fish were fed commercial pellet feed (Aller-Aqua,

87 Denmark) at rations designed for maximum growth. The trout originated from a migratory

88 breeding stock from the nearby River Klarälven. The Klarälven trout are landlocked and

89 historically migrated between Lake Vänern $\left(5650 \mathrm{~km}^{2}\right)$ and their spawning grounds, up to

$90400 \mathrm{~km}$ upstream. In the 1900s hydropower development blocked migration in all but the

91 lower $25 \mathrm{~km}$ of the river (Norrgård 2011). To compensate, the Gammelkroppa fish farm

92 operates an annual restocking programme for brown trout and Atlantic salmon in the River

93 Klarälven. Klarälven trout raised for restocking typically smolt, and are released in their $3^{\text {rd }}$

94 spring (i.e. aged 2+). 
95 A total of 3840 fish, aged 1+, were transferred in oxygenated tanks from the nearby

96 Gammelkroppa fish farm and randomly placed into $241.25 \times 1.25$ m tanks (160 ind. $\left.\operatorname{tank}^{-1}\right)$ on 21 September 2010. An additional 340 replacements for fish that died were split between 2 tanks. Water circulation was continuous and supplied by an adjacent stream. The tanks were indoors but windows and skylights meant that fish were reared under ambient photoperiod.

\section{Experimental design and initial measurements}

Initial fish fork length and mass were measured for all fish in 4 randomly selected tanks $(n=$ 640). Condition factor was calculated by regressing weight against length and using the residuals to indicate condition variation. A subsample $(n=25$, total $n=500)$ from the remaining 20 tanks were measured to ensure no significant differences in length or mass occurred among tanks. The number of precociously mature males recorded during measuring was only $\sim 5 \%$, and we did not exclude them from the experiment because their occurrence was randomly distributed among tanks. Treatments were randomly assigned to the hatchery tanks. Fish were subjected to 1 of 6 different food treatments, each replicated 4 times. Treatments included a high ration control (fish fed high rations for the entire experiment), a low ration control (fish starved for the duration of the experiment) and four other treatments which involved starving fish in autumn, winter or spring (Table 1). The amount of food administered to the fish was adjusted based on water temperature and the biomass of fish in each tank. High food rations were chosen according to hatchery guidelines for achieving maximum fish growth. Low food rations were $30 \%$ of high rations (see Table 1 for approx. rations fed to fish). Fish were fed commercial food pellets (Aller-Aqua, Denmark) administered by automated dispensers. Food was dispensed to low ration treatments for 2

117 hours in the morning and 2 hours in the evening. High ration treatments received food for 3 118 hours in the morning and 3 hours in the evening. Temperature was recorded hourly using 4 
temperature loggers $(\mathrm{HOBO})$ placed in 4 separate tanks. Mean daily temperatures were calculated by averaging all daily readings.

\section{Sampling regime}

Each sampling event occurred prior to a change in feeding regime. As such, fish were measured at the beginning of the experiment (September), at the end of autumn (December), the end of winter (March) and the end of spring (May). At each sampling event the length and mass of 50 haphazardly selected individuals from each tank were measured.

Smolt state was recorded for individuals in May (late April through to May is the regular smolting season for trout in Klarälven). Smolt state was judged on a three point scale according to Tanguy et al. (1994). Morphological metrics (silvering, loss of pigment from the fins, loss of parr marks, and prominent lateral line) have been shown to be correlated with, and in some cases more reliable than, physiological measures (such as gill $\mathrm{NA}+$ and $\mathrm{K}+$ ATPase and saltwater tolerance challenge tests) in predicting migration in trout (Debowski et al. 1999). Furthermore, Atlantic salmon in the Klarälven system are known to change both morphologically and physiologically prior to outmigration (Norrgård et al. 2014a, Norrgård et al. 2014b) and fully-silvered fish migrate faster and have a greater migration success than fish with less developed morphological smolt characteristics (Norrgård et al. 2014b). We assumed fish that showed at least two clear signs of smoltification (two of the following: silvering and loss of parr marks, prominent lateral line, loss of pigment from the fins) were in the process of developing full smoltification (pre-smolt). As such, fish displaying pre-smolt or smolt morphologies (categories 2 and 3) were classified as smolts. Fish displaying parr morphologies (category 1) were classified as residents.

A subsample of fish was sacrificed for lipid content analysis; we used mid-infrared transmission spectroscopy (Elvingson and Sjaunja 1992) to measure lipid content and 
144 determine how starvation affected the lipid content of fish. This was done at the start $(n=20$

145 haphazardly selected individuals) and at the end of each season (2 or 3 individuals sampled

146 haphazardly from each tank; $n=10$ individuals per treatment per sample event). In addition

147 to lipid content analysis, we recorded fish fork length, mass and sex (after inspection of

148 gonads).

150 Statistical analysis

151 All statistical analysis and graphing were carried out using the "ez" (Lawrence 2013),

152 “scales" (Wickham 2014), "lme4” (Bates et al. 2013), “arm” (Gelman and Su 2014),

153 “plotrix” (Lemon 2006), “gplots” (Warnes et al. 2015), “pbkrtest” (Halekoh and Højsgaard

154 2014) and "stats" packages in R version 3.1.1 (R Core Team 2014).

155

156

157

\section{Growth, condition factor and fat content}

To test for an overall effect of food treatment and time on fish length, mass, condition factor and fat content we performed Linear Mixed Effects Models (LMMs) on each response variable and time period, with tank ID as a random factor. Models were validated visually by plotting residuals against fitted values (homogeneity), QQ-plots and histograms of residuals (normality), and plotting residuals against explanatory variables (violating independence).

\section{Proportion of smolts}

Smolts were classified as those fish which were not clearly parr (smolts were fish that displayed any sign of smolting, i.e. with scores $\geq 2$ ) and the proportion of smolts was analysed using Generalised Linear Mixed Effects Models (GLMMs). We analysed the proportion data using a logit-link function and binomial error structure. Our explanatory factors were starvation period (autumn, winter, spring), fish length at time of sampling (mm), and interactions between starvation period and fish length; tank nested within treatment were included as a random effects. Length was centred so that intercepts were meaningful 
169 (Schielzeth 2010). Whilst temperature was the same for all treatments, and food availability 170 controlled, we could not control for differences in individual growth rates, and it was for this reason we included length in the GLMM. Mass and condition factor were not included in the models because they are highly dependent on treatment (i.e. food availability). Lipid content was not included in the model because we only measured lipid content for a small subsample of fish ( $n=10$ per treatment for lipids, compared with $n=200$ per treatment for measures of length). We began with the fullest model including all possible interaction terms. Using the "drop1" function with the chi-square test, we removed explanatory variables sequentially and compared the difference in model deviances to a chi-square distribution with the appropriate degrees of freedom. In all instances we tried to achieve the most parsimonious model. In cases where a simpler model was not significantly different from the fuller model (by checking AIC scores using the drop1 function, and using the "ANOVA" function to compare models), we chose the simpler.

182

\section{Results}

\section{Length, weight, condition factor and fat content}

No differences in fish length were found between treatments until May. In May fish length in treatments that were starved in spring were significantly lower than the high control $(T=-$ $3.28, p<0.01 ; \mathrm{T}=-3.89, p<0.01 ; \mathrm{T}=-3.96, p<0.01$ for treatments HHL, HLL and LLL respectively). Fish length in treatments LHH and LLH did not differ significantly from the high control (Figure 1).

Differences in fish mass were found between treatments in both March and May. In March fish mass was significantly lower in all treatments compared with the high control $(\mathrm{T}=-3.22$, $p<0.01 ; \mathrm{T}=-2.23, p<0.05 ; \mathrm{T}=-2.50, p<0.05$ for treatments HL, LH and LL respectively). In May fish mass was significantly lower in treatments HHL $(\mathrm{T}=-6.41, p<0.01)$, HLL $(\mathrm{T}=$ -7.77, $p<0.01)$, LHH $(\mathrm{T}=-2.43, p<0.05)$ and LLL $(\mathrm{T}=-7.46, p<0.01)$ compared with the 
194 high control. Fish mass in treatment LLH did not differ significantly from the high control in 195 May (Figure 1).

196

Differences in fish condition factor were found between treatments in December, March and May. In December fish fed low food rations had a significantly lower condition than fish fed high rations $(\mathrm{T}=-3.77, p<0.01)$. In March fish condition was significantly lower in treatments starved over winter compared with the high control $(\mathrm{T}=-6.20, p<0.01 ; \mathrm{T}=-$ $6.79, p<0.01$ for treatments HL and LL respectively). Fish condition in treatment LH did not differ significantly from the high control. In May fish from all the treatments starved over spring had a significantly lower condition compared with the high control $(\mathrm{T}=-9.15, p<$ $0.01 ; \mathrm{T}=-11.30, p<0.01 ; \mathrm{T}=-10.26, p<0.01$ for treatments HHL, HLL and LLL respectively). Fish condition in treatments LHH and LLH did not differ significantly from the high control (Figure 1).

Differences in fish lipid content were found between treatments in March and May. In March fish lipid content was significantly lower in treatments starved over winter compared with the high control $(\mathrm{T}=-3.22, p<0.01 ; \mathrm{T}=-2.67, p<0.01$; for treatments $\mathrm{HL}$ and $\mathrm{LL}$ respectively). In May fish from all the treatments starved over spring had a significantly lower condition compared with the high control $(\mathrm{T}=-5.41, p<0.01 ; \mathrm{T}=-8.48, p<0.01 ; \mathrm{T}=$ $-5.41, p<0.01$ for treatments HHL, HLL and LLL respectively). Fish condition in treatments LHH and LLH did not differ significantly from the high control (Figure 1).

\section{Proportion of smolts}

The proportion of smolts in May was greater for the three treatments in which trout were starved over spring (93-95\%) than for the high control treatment (79\%). Treatment alone was not sufficient to predict whether or not a fish became a smolt. A series of GLMMs used to predict the proportion of smolts $\left(S_{m}\right)$, based on starvation period (autumn, winter, spring), fish 
218 length at time of sampling, and interactions between starvation period and fish length, were 219 run and resulted in a best fit model containing the terms spring starved $\left(S_{S}\right)$, length $(L)$ and the interaction term $S_{s} L$.

$$
S_{m}=S_{S}+L+S_{S} * L
$$

222 Fish starved in autumn and winter were not significantly more likely to be smolts in spring, and both were also discarded from the best model according to AIC scores. Starvation in spring significantly increased the likelihood of smoltification $(\mathrm{z}=3.05, \mathrm{p}<0.01$; Table 2 , Figure 2). Fish length had a significant effect on the proportion of smolts; longer fish were more likely to be classified as smolts $(\mathrm{z}=6.95, p<0.01$; Figure 2$)$, the spring starved * length interaction term was also significant; longer fish in spring starved treatments were more likely to be classified as smolts $(\mathrm{z}=2.28, \mathrm{p}<0.05)$. Treatment had a negligible amount of variance and was discarded as a random variable from the best model.

\section{Discussion}

The present study indicates that spring food availability influences smolt status in brown trout. Recent studies have shown that food availability is one factor that influences whether brown trout becomes a migrant or not (Olsson et al. 2006, Wysujack et al. 2009). However, these studies did not investigate when the decision was made (sensu Metcalfe et al. 1986, 1988, Vainikka et al. 2012 for Atlantic salmon), just that food restrictions prior to migration increased the number of migrants in the population. Our study demonstrates that less food increases the probability of becoming a smolt, i.e. a migrant, but it also pinpoints that food availability during the spring is important. 
242 Whilst they are different species, they share a near identical life history and their habitats

243 often overlap. Both species demonstrate residency, migration or partial migration, though

244 Atlantic salmon appear more predisposed to a migratory life history (Klemetsen et al. 2003,

245 Jonsson and Jonsson 2011b). It is not unreasonable to assume that common environmental

246 conditions cause migration across these species (Jonsson and Jonsson 2011b). One possible

247 explanation is that the present work is performed in an inland system, whereas Metcalfe et al.

$248(1986,1988)$ studied anadromous fish. Another explanation may be because brown trout are

249 more facultative than Atlantic salmon in their migratory response (Bohlin et al. 2001,

250 Klemetsen et al. 2003). A meta-analysis of the effects of food rationing on out-migration in

251 salmonids revealed contrasting migratory strategies in response to food limitation (D. A.

252 Jones, G. P. Closs, M. Lagisz and S. Nakagawa unpublished). This meta-analysis revealed

253 that some salmonid species such as Atlantic salmon do not readily increase out-migration in

254 response to food limitation, whereas other species such as brown trout do. Smoltification in

255 the present system appears to be more facultative and influenced by current food availability.

256 In contrast to Metcalfe et al. $(1986,1988)$, and similar to our results on brown trout, Vainikka

257 et al. (2012) found that there was a facultative element to smoltification and migration in

258 Atlantic salmon. They found that a change in food rations in winter and spring prior to

259 migration could affect smoltification and migratory speed. These variable findings

260 underscore the complexity of migratory decision making and might be an indication of high

261 inter- and intraspecies variability in migratory response to environmental conditions.

262 The relationship between growth, migration and maturation is complex. For more obligate

263 migrators the conditional strategy states that if individuals attain a threshold value the

264 previous year, migration may take place the following spring. However, maturation should be

265 favoured over smolting when resource availability is high (Thorpe 1994, Thorpe and

266 Metcalfe 1998). Indeed, Vainikka et al. (2012) showed that decreasing abundant food rations 
267 in the hatchery could reduce maturation and increase migration in Atlantic salmon. Fish in 268 our experiment had access to unlimited food resources prior to autumn, yet the number of 269 mature fish was low $(\sim 5 \%)$. Also, food limitation in the autumn reduced mass and significantly reduced condition factor but did not affect the proportion of smolts the

271 following spring.

272 Generally, fast growing fish are more likely to migrate (Acolas et al. 2012) than slow 273 growing fish, although Jonsson (1985) and Ricker (1975) showed that both the fastest 274 growing and the slowest growing fish (brown trout and sockeye salmon) smolt and fish with 275 intermediate growth rates become sexually mature as parr instead (see also Fig. 5.9 in 276 Jonsson and Jonsson (2011a)). Our study showed that it was not only fast growth that caused 277 increased smoltification, but rather the combination of high growth and reduced rations in spring. A likely interpretation of this discrepancy is that under full rations, as in our experiment, individuals are in good condition, able to maintain growth, and thus fewer smolt (Jonsson and Jonsson 1993, Forseth et al. 1999).

That trout smolted even in the full ration treatments might indicate that not all individuals in these treatments were able to maintain growth. In general longer fish were more likely to be classified as smolts, regardless of treatment, which could indicate that larger individuals have norm for migration, analogous to the situation described for maturation in white-spotted charr, Salvelinus leucomaenis (Morita et al. 2009). Thus, when food is abundant, fish with a lower growth rate presumably have little need to migrate to a resource-rich environment 291 (lakes or the sea). 
292 It is important to remember that our findings are the result of experiments on fish in a

293 hatchery environment. As always, a level of caution is required before extrapolating these

294 results to natural fish populations. However, we think the results are relevant given the

295 importance of hatchery-derived restocking schemes. Also, it is most likely that in natural

296 environments where competition is high, the effect of spring limitation would be felt more

297 acutely, and its effect on smoltification could be greater.

298 The amount of food fish received affected indices of growth, condition factor and smolt

299 status. Significant differences in fish condition were evident between high and low ration

300 treatments after just one season (autumn), and mass after two seasons (autumn and winter).

301 Differences were more pronounced after winter and, especially, spring. It is worth noting that

302 fish that were previously starved were able to recover mass and condition factor if placed on

303 a high ration diet. Fat content was less sensitive to changes in food rationing but differences

304 were evident after winter, and markedly different by May. Length was least sensitive to food

305 rationing. Only in May were differences in fish length observed between fish fed high and

306 low rations. Length depends on inherited growth rates (Thorpe and Morgan 1978), but

307 starvation during spring appears to limit length growth. Despite an overall reduced growth in

308 spring starved treatments, larger individuals in these treatments were more likely to migrate

309 than in treatments where fish were administered full rations in spring. That starvation in

310 spring had the largest effect on growth metrics and the proportion of smolts, suggests that

311 individuals smolted because they were unable to maintain growth in their current

312 environment. This is in full agreement with work carried out on brook charr (Morinville and

313 Rasmussen 2003) and brown trout (Jonsson and Jonsson 1993, Forseth et al. 1999).

314 It is probable that environment shapes migratory decisions by salmonids, as has also been

315 shown for insects (Taylor and Taylor 1977). Migration may be a mechanism used to avoid

316 metabolic adversity (Forseth et al. 1999), and obtain energy required to grow and mature 
317 (Thorpe 1994, Thorpe and Metcalfe 1998). We found that larger fish on reduced rations were 318 more likely to smolt. Fish with higher growth rates have greater metabolic requirements and 319 are more likely to migrate when resources are limiting (Forseth et al. 1999). Larger fish are 320 also most likely to survive migratory journeys (Bohlin et al. 1993, Jonsson and Jonsson 321 2014). A restriction in food availability in natal streams promotes migration; a life history 322 which is sustained if food availability is higher at migratory destinations. Conversely, if there 323 is no growth advantage from migrating then residency is favoured. Switches between migratory and resident life histories have been observed in wild populations of Arctic charr and brown trout (Näslund et al. 1993, Sandlund and Jonsson 2014).

In conclusion, this study demonstrates that smolting is flexible in brown trout and can be influenced by feeding conditions in spring. The situation for brown trout does not seem to resemble that of Atlantic salmon as described by Metcalfe et al. $(1986,1988)$, namely that the decision to migrate in spring depends on whether an energetic or a size threshold is reached in the previous summer, but is in line with work carried out by Vainikka et al. (2012). The majority of studies investigating the effect of food availability show that brown trout respond to reduced food by increasing smoltification and outmigration. According to the conditional strategy, individuals migrate if they are able to achieve a predetermined threshold; individuals that cannot achieve this delay migration. Instead we found that smolting in spring was highest in treatments where measures of growth were reduced.

\section{Acknowledgements}

337 Thanks to Linnea Lans, Richard Gow and Erland Karlsson for help in the hatchery. Thanks 338 also to the staff at Brattfors and Gammelkroppa fish farms for help, advice and provision of 339 fish. We would also like to acknowledge Shinichi Nakagawa for statistical advice, and Agnes 340 Karlson, Gerry Closs, and three anonymous reviewers for valuable comments. 


\section{References}

Acolas, M.L., Labonne, J., Bagliniere, J.L., and Roussel, J.M. 2012. The role of body size versus growth on the decision to migrate: a case study with Salmo trutta. Naturwissenschaften 99(1): 1121.

Bates, D., Maechler, M., and Bolker, B. 2013. Ime4: Linear mixed-effects models using S4 classes. Bergman, E., Piccolo, J., and Greenberg, L. 2013. Raising brown trout (Salmo trutta) with less food effects on smolt development and fin damage. Aquaculture Research 44(6): 1002-1006.

Boel, M., Aarestrup, K., Baktoft, H., Larsen, T., Søndergaard Madsen, S., Malte, H., Skov, C., Svendsen, J.C., and Koed, A. 2014. The physiological basis of the migration continuum in brown trout (Salmo trutta). Physiological and Biochemical Zoology 87(2): 334-345.

Bohlin, T., Dellefors, C., and Faremo, U. 1993. Optimal time and size for smolt migration in wild seatrout (Salmo trutta). Canadian Journal of Fisheries and Aquatic Sciences 50(2): 224-232.

Bohlin, T., Pettersson, J., and Degerman, E. 2001. Population density of migratory and resident brown trout (Salmo trutta) in relation to altitude: evidence for a migration cost. Journal of Animal Ecology 70(1): 112-121.

Debowski, P., Glogowski, J., Robak, S., and Dobosz, S. 1999. Gill Na+, K+-ATPase activity and body silvering as indices of smoltification of hatchery-reared sea trout. Archives of Polish Fisheries 7: 245-256.

Elliott, J.M. 1994. Quantitative ecology and the brown trout. Oxford University Press, Oxford.

Elvingson, P., and Sjaunja, L.O. 1992. Determination of fat protein and dry matter content of fish by mid-infrared transmission spectroscopy. Aquaculture and Fisheries Management 23(4): 453460.

Forseth, T., Naesje, T.F., Jonsson, B., and Harsaker, K. 1999. Juvenile migration in brown trout: a consequence of energetic state. Journal of Animal Ecology 68(4): 783-793.

Gelman, A., and Su, Y.-S. 2014. arm: Data Analysis Using Regression and Multilevel/Hierarchical Models.

Gross, M.R., Coleman, R.M., and McDowall, R.M. 1988. Aquatic productivity and the evolution of diadromous fish migration. Science 239(4845): 1291-1293.

Halekoh, U., and Højsgaard, S. 2014. A Kenward-Roger approximation and parametric bootstrap methods for tests in linear mixed models-the R package pbkrtest. Journal of statistical software 59(9): 1-32.

Heino, M., Dieckmann, U., and Godø, O.R. 2002. Measuring probabilistic reaction norms for age and size at maturation. Evolution 56(4): 669-678.

Imre, I., Grant, J.W.A., and Keeley, E.R. 2004. The effect of food abundance on territory size and population density of juvenile steelhead trout (Oncorhynchus mykiss). Oecologia 138(3): 371-378.

Jonsson, B. 1985. Life History Patterns of Freshwater Resident and Sea-Run Migrant Brown Trout in Norway. Transactions of the American Fisheries Society 114(2): 182-194.

Jonsson, B., and Jonsson, N. 1993. Partial migration - niche shift versus sexual-maturation in fishes. Reviews in Fish Biology and Fisheries 3(4): 348-365.

Jonsson, B., and Jonsson, N. 2011a. Ecology of Atlantic Salmon and Brown Trout. Habitat as a template for life histories. In Fish \& Fisheries Series. Springer.

Jonsson, B., and Jonsson, N. 2011b. Ecology of Atlantic Salmon and Brown Trout: Habitat as a Template for Life Histories. In Ecology of Atlantic Salmon and Brown Trout: Habitat as a Template for Life Histories.

Jonsson, N., and Jonsson, B. 2014. Time and size at seaward migration influence the sea survival of Salmo salar. Journal of Fish Biology 84(5): 1457-1473.

Keeley, E.R. 2001. Demographic responses to food and space competition by juvenile steelhead trout. Ecology 82(5): 1247-1259. 
Klemetsen, A., Amundsen, P.A., Dempson, J.B., Jonsson, B., Jonsson, N., O'Connell, M.F., and Mortensen, E. 2003. Atlantic salmon Salmo salar L., brown trout Salmo trutta L. and Arctic charr Salvelinus alpinus (L.): a review of aspects of their life histories. Ecology of Freshwater Fish 12(1): 1-59.

Kuparinen, A., O'Hara, R.B., and Merilä, J. 2008. Probabilistic models for continuous ontogenetic transition processes. Plos One 3(11): e3677.

Lawrence, M.A. 2013. ez: Easy analysis and visualization of factorial experiments.

Lemon, J. 2006. Plotrix: a package in the red light district of R. R-News. R-News 6(4): 8-12.

Metcalfe, N.B., Huntingford, F.A., and Thorpe, J.E. 1986. Seasonal changes in feeding motivation of juvenile Atlantic salmon (Salmo salar). Canadian Journal of Zoology 64(11): 2439-2446.

Metcalfe, N.B., Huntingford, F.A., and Thorpe, J.E. 1988. Feeding intensity, growth-rates, and the establishment of life-history patterns in juvenile Atlantic salmon Salmo salar Journal of Animal Ecology 57(2): 463-474.

Morgan, I.J., McCarthy, I.D., and Metcalfe, N.B. 2002. The influence of life-history strategy on lipid metabolism in overwintering juvenile Atlantic salmon. Journal of Fish Biology 60(3): 674-686.

Morinville, G.R., and Rasmussen, J.B. 2003. Early juvenile bioenergetic differences between anadromous and resident brook trout (Salvelinus fontinalis). Canadian Journal of Fisheries and Aquatic Sciences 60(4): 401-410.

Morita, K., Tamate, T., Kuroki, M., and Nagasawa, T. 2014. Temperature-dependent variation in alternative migratory tactics and its implications for fitness and population dynamics in a salmonid fish. Journal of Animal Ecology.

Morita, K., Tsuboi, J.-I., and Nagasawa, T. 2009. Plasticity in probabilistic reaction norms for maturation in a salmonid fish. Biology Letters: rsbl20090290.

Näslund, I., Milbrink, G., Eriksson, L., and Holmgren, S. 1993. Importance of habitat productivity differences, competition and predation for the migratory behaviour of Arctic charr. Oikos: 538-546.

Norrgård, J.R. 2011. Landlocked Atlantic salmon Salmo salar L. and trout Salmo trutta L. in the regulated River Klarälven, Sweden. Implications for conservation and management. Licenciate, Faculty of Social and Life Sciences, Biology, Karlstad University, Karlstad.

Norrgård, J.R., Bergman, E., Greenberg, L.A., and Schmitz, M. 2014a. Effects of feed quality and quantity on growth, early maturation and smolt development in hatchery-reared landlocked Atlantic salmon Salmo salar. Journal of Fish Biology 85(4): 1192-1210.

Norrgård, J.R., Bergman, E., Schmitz, M., and Greenberg, L.A. 2014b. Effects of feeding regimes and early maturation on migratory behaviour of landlocked hatchery-reared Atlantic salmon Salmo salar smolts. Journal of Fish Biology 85(4): 1060-1073.

Olsson, I.C., Greenberg, L.A., Bergman, E., and Wysujack, K. 2006. Environmentally induced migration: the importance of food. Ecology Letters 9(6): 645-651.

Pirhonen, J., and Forsman, L. 1998. Effect of prolonged feed restriction on size variation, feed consumption, body composition, growth and smelting of brown trout, Salmo trutta. Aquaculture 162(3-4): 203-217.

R Core Team. 2014. R: A Language and Environment for Statistical Computing. Vienna, Austria.

Railsback, S.F., and Rose, K.A. 1999. Bioenergetics Modeling of Stream Trout Growth: Temperature and Food Consumption Effects. Transactions of the American Fisheries Society 128(2): 241256.

Ricker, W.E. 1975. Computation and interpretation of biological statistics of fish populations. Bulletin of the Fisheries Research Board of Canada 191: 1-382.

Sandlund, O.T., and Jonsson, B. 2014. Life history plasticity: migration ceased in response to environmental change? Ecology of Freshwater Fish: n/a-n/a.

Schielzeth, H. 2010. Simple means to improve the interpretability of regression coefficients. Methods in Ecology and Evolution 1(2): 103-113. 
Tanguy, J.M., Ombredane, D., Bagliniere, J.L., and Prunet, P. 1994. Aspects of parr smolt transformation in anadromous and resident forms of brown trout (Salmo trutta) in comparison with Atlantic salmon (Salmo salar). Aquaculture 121(1-3): 51-63.

Taylor, L., and Taylor, R. 1977. Aggregation, migration and population mechanics. Nature 265(5593): 415-421.

Thorpe, J.E. 1994. An alternative view of smolting in salmonids. Aquaculture 121(1-3): 105-113.

Thorpe, J.E., and Metcalfe, N.B. 1998. Is smolting a positive or a negative developmental decision? Aquaculture 168(1-4): 95-103.

Thorpe, J.E., and Morgan, R.I.G. 1978. Parental influence on growth rate, smolting rate and survival in hatchery reared juvenile Atlantic salmon, Salmo salar. Journal of Fish Biology 13(5): 549556.

Vainikka, A., Huusko, R., Hyvärinen, P., Korhonen, Pekka K., Laaksonen, T., Koskela, J., Vielma, J., Hirvonen, H., and Salminen, M. 2012. Food restriction prior to release reduces precocious maturity and improves migration tendency of Atlantic salmon (Salmo salar) smolts. Canadian Journal of Fisheries and Aquatic Sciences 69(12): 1981-1993.

Warnes, G.R., Bolker, B., Bonebakker, L., Gentleman, R., Liaw, W.H.A., Lumley, T., Maechler, M., Magnusson, A., Moeller, S., Schwartz, M., and Venables, B. 2015. gplots: Various R Programming Tools for Plotting Data.

Wickham, H. 2014. scales: Scale functions for graphics.

Wilzbach, M.A. 1985. Relative roles of food abundance and cover in determining the habitat distribution of stream-dwelling cutthroat trout (Salmo clarki). Canadian Journal of Fisheries and Aquatic Sciences 42(10): 1668-1672.

Wysujack, K., Greenberg, L.A., Bergman, E., and Olsson, I.C. 2009. The role of the environment in partial migration: food availability affects the adoption of a migratory tactic in brown trout Salmo trutta. Ecology of Freshwater Fish 18(1): 52-59. 

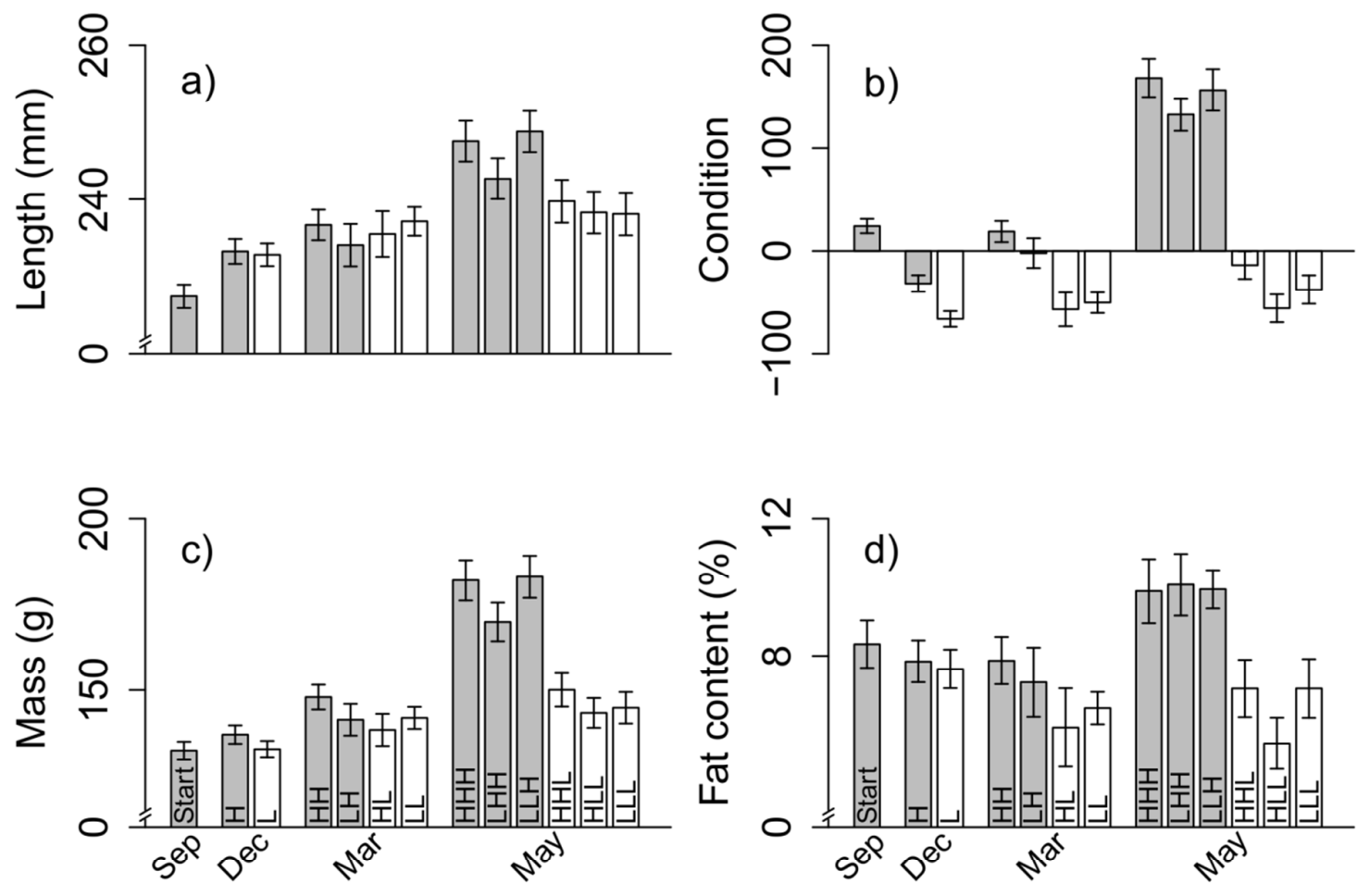

467

468 Figure 1. Seasonal development of the a) length, b) condition, c) mass, and d) fat content of

469 trout from all treatments during the experiment. Grey bars indicate high rations in the

470 preceding season, white bars indicate low rations in the preceding season. Treatment labels

471 are included; L represents low food rations, $\mathrm{H}$ represents high rations. Values are means

$472 \pm 95 \%$ confidence intervals. 


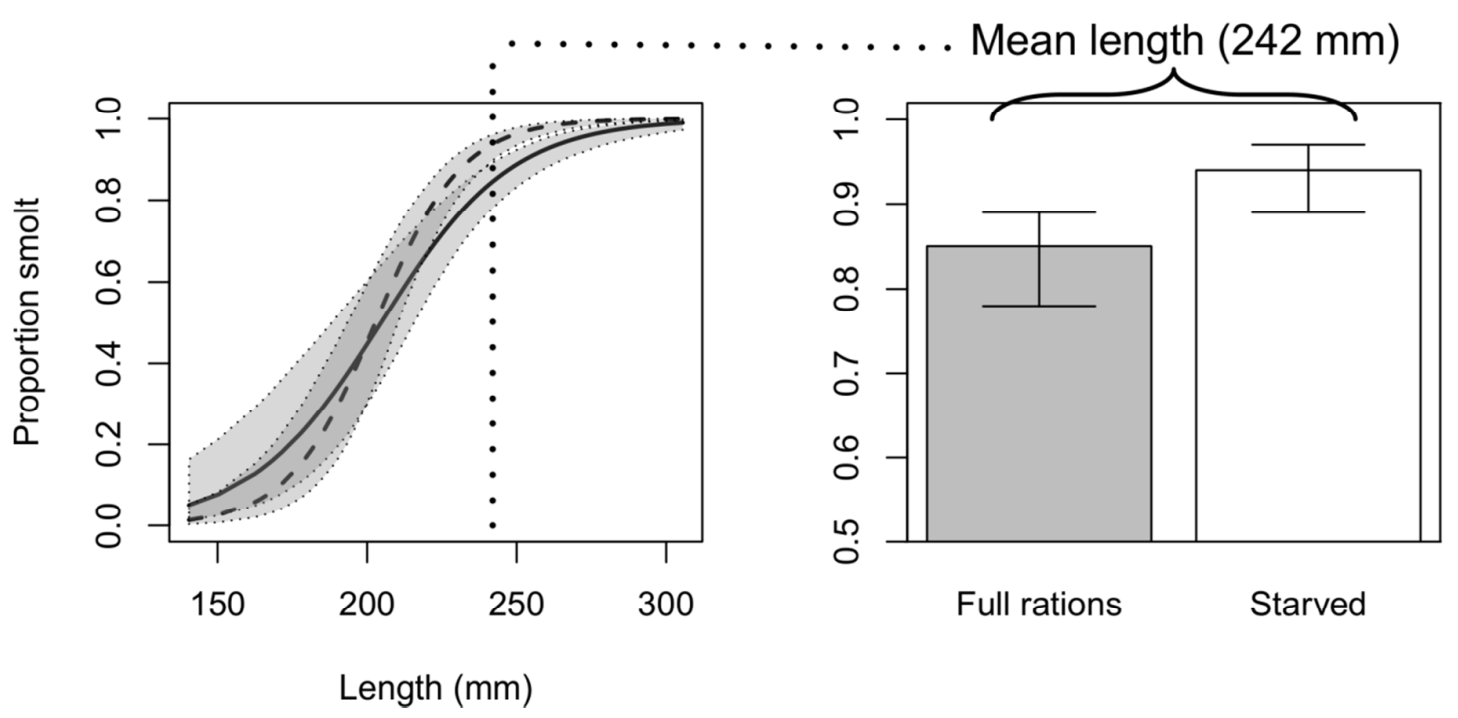

474 Figure 2. Probability of the fish being classified as a smolt based on length in May according

475 to our Generalised Linear Mixed Effects Model. Dashed line represents spring starved fish,

476 solid line is fish fed full rations. Panel to the right shows the probability of a $242 \mathrm{~mm}$ (mean

477 length of fish in May) long fish being classified as a smolt, based on food rations. Shading

478 around lines and the error bars in the bar graph represent $\pm 95 \%$ confidence intervals. Note

479 that greater differences likely occur in fish at lower lengths, but since we had few fish in

480 these size classes estimates are less accurate and confidence intervals are larger.

481

482

483

484

485

486

487

488

489

490 
491 Table 1. Six different food ration treatments with details of food treatments for autumn,

492 winter and spring periods. Approximate rations for each season (grams per individual per 493 week) are given in brackets.

\begin{tabular}{|c|c|c|c|}
\hline Treatment & $\begin{array}{l}\text { Food ration } \\
\text { autumn }\end{array}$ & $\begin{array}{l}\text { Food ration } \\
\text { winter }\end{array}$ & $\begin{array}{l}\text { Food ration } \\
\text { spring }\end{array}$ \\
\hline & $\left(\sim \mathrm{g} \mathrm{ind}^{-1}\right.$ week $^{-1} /$ & $\left(\sim \mathrm{g} \mathrm{ind}^{-1}\right.$ week $^{-1} /$ & $\left(\sim \mathrm{g}_{\text {ind }}{ }^{-1}\right.$ week $^{-1} /$ \\
\hline & $\sim \%$ mass ind ${ }^{-1}$ ) & $\sim \%$ mass ind $\left.{ }^{-1}\right)$ & $\sim \%$ mass ind ${ }^{-1}$ ) \\
\hline HHH (high ration control) & High $(6.9 / 0.72)$ & High $(2.9 / 0.31)$ & High $(7.3 / 1.00)$ \\
\hline LLL (low ration control) & Low $(2.1 / 0.22)$ & Low $(0.9 / 0.10)$ & Low $(2.2 / 0.30)$ \\
\hline HLL & & Low $(0.9 / 0.10)$ & Low $(2.2 / 1.00)$ \\
\hline LHH & & High $(2.9 / 0.31)$ & High $(7.3 / 0.30)$ \\
\hline HHL & & & Low $(2.2 / 1.00)$ \\
\hline LLH & & & High $(7.3 / 0.30)$ \\
\hline
\end{tabular}


506 Table 2. Coefficients and their standard errors for the proportion of smolts.

\begin{tabular}{lcccc}
\hline Effect & Lower 95 \% CI & Coefficient estimate & Upper 95 \% CI & $\mathrm{z}-$ value \\
\hline Spring fed & 1.28 & 1.70 & 2.12 & 7.96 \\
Spring starved & 2.06 & 2.71 & 3.36 & 3.05 \\
Length*fed & 0.03 & 0.05 & 0.06 & 6.95 \\
Length*starved & 0.04 & 0.07 & 0.10 & 2.28
\end{tabular}

507 Note: Response is migrant or not migrant. The estimates for the categorical spring fed and

508 spring starved are for the intercepts. Length*fed and Length*starved are numerical and their

509 estimates are coefficients for the slope. The $\mathrm{z}$ - value and probabilities of obtaining the $\mathrm{z}-$

510 value by chance are provided. The $\mathrm{z}$ - value is the number of standard deviations from the

511 reference value. Note that values are the logit of predicted values. 